\title{
Miconia lucenae (Melastomataceae), a new species from montane Atlantic Forest in Espírito Santo, Brazil
}

\author{
Renato Goldenberg ${ }^{\text {Corresp., }}{ }^{,}$, Marcelo Reginato ${ }^{2}$, Fabian A Michelangeli ${ }^{3}$ \\ ${ }^{1}$ Departamento de Botânica, Universidade Federal do Paraná, Curitiba, Paraná, Brazil \\ 2 Departamento de Botânica, Universidade Federal do Rio Grande do Sul, Porto Alegre, Rio Grande do Sul, Brazil \\ 3 Institute of Systematic Botany, The New York Botanical Garden, New York, United States of America \\ Corresponding Author: Renato Goldenberg \\ Email address: rgolden@ufpr.br
}

We describe Miconia lucenae R.Goldenb. \& Michelang., a new species from montane Atlantic Forest in Santa Teresa, state of Espírito Santo. Our analysis based on three plastid spacers (atpF-atpH, psbK-psbl and trnS-trnG), one plastid gene ( $n d h F$, not available for $M$. lucenae), and two nuclear ribosomal loci (nrITS and nrETS) showed that it belongs to a small clade with Miconia paradoxa (Mart. ex DC.) Triana (Minas Gerais) and M.

michelangeliana R.Goldenb. \& L.Kollmann (Espírito Santo). The three species in "Paradoxa clade" can be recognized by the plants with glabrous or glabrescent branches and leaves, white petals and yellow stamens, these with the connectives not prolonged bellow the thecae, ventrally unappendaged, dorsally unappendagged or with a minute tooth, the latter bilobed or not, glabrous ovary, and the fruits with a persistent calyx. Miconia lucenae can be recognized, among the species in this clade, by the shrubby plants with terete young branches, short inflorescences, usually with red axes, and the 2-bracteolate, sessile, 4-merous flowers, with a ciliolate inner portion of the sepals, lanceolate petals, and 4celled ovaries. This species can be considered as endangered, according to IUCN criteria. 


\section{Miconia Iucenae (Melastomataceae), a new species}

3 from montane Atlantic Forest in Espírito Santo, Brazil.

4

5

Renato Goldenberg ${ }^{1}$, Marcelo Reginato ${ }^{2} \&$ Fabián A. Michelangeli ${ }^{3}$

${ }^{1}$ Departamento de Botânica, Universidade Federal do Paraná, Curitiba, Paraná, Brazil.

${ }^{2}$ Departamento de Botânica, Universidade Federal do Rio Grande do Sul, Porto Alegre, Rio Grande do Sul, Brazil.

${ }^{3}$ Institute of Systematic Botany, The New York Botanical Garden. Bronx, New York, USA

Corresponding Author:

Renato Goldenberg ${ }^{1}$

Av. Francisco H. dos Santos s.n., Centro Politécnico/UFPR, Depto Botânica, Caixa Postal 19031, Curitiba, Paraná, 81531-970, Brazil

Email address: rgolden@ufpr.br

\section{Abstract}

We describe Miconia lucenae R.Goldenb. \& Michelang., a new species from montane Atlantic Forest in Santa Teresa, state of Espírito Santo, Brazil. Our analysis based on three plastid spacers (atpF-atpH, psbK-psbI and trnS-trnG), one plastid gene ( $n d h F$, not available for M. lucenae), and two nuclear ribosomal loci (nrITS and nrETS) showed that it belongs to a small clade with Miconia paradoxa (Mart. ex DC.) Triana (Minas Gerais) and M. michelangeliana R.Goldenb. \& L.Kollmann (Espírito Santo). The three species in the "Paradoxa clade" are recognized by glabrous or glabrescent branches and leaves, white petals and yellow stamens, these with connectives not prolonged below the thecae, ventrally unappendaged, dorsally unappendagged or with a minute tooth, the latter bilobed or not, glabrous ovaries, and fruits with a persistent calyx. Miconia lucenae is distinguished by shrubby habit, terete young branches, short inflorescences, usually with red axes, and 2-bracteolate, sessile, 4-merous flowers, with a ciliolate inner portion of the sepals, lanceolate petals, and 4-celled ovaries. This species can be considered as endangered, according to IUCN criteria. 


\section{Introduction}

37 Miconia Ruiz \& Pav. has nowadays about ca. 1900 species native to the Neotropics

38 (Michelangeli et al., 2016). Its circumscription has been recently modified (see Michelangeli et 39 al., 2016, 2019), and now it is equivalent to the whole tribe Miconieae, in its modern definition

40 (Michelangeli et al., 2004, 2008; Goldenberg et al., 2008; see also Penneys et al., 2010;

41 Michelangeli et al., 2011). This new circumscription includes former Miconia sensu stricto and 42 several other genera, such as Leandra Raddi, Clidemia D.Don, Ossaea DC. and Tococa Aubl.

43 Some of these genera or parts of these genera may be monophyletic (Reginato \& Michelangeli, 44 2016), but their recognition renders Miconia s.s. paraphyletic. For an alternative opinion on this broad circumscription of Miconia see Kriebel (2016) and Reginato (2016).

In the course of floristic work in the state of Espírito Santo, Brazil, we collected an undescribed species with lanceolate petals and terminal inflorescences. In Cogniaux's (1891) classification, this species would have been placed in Leandra. However, the general floral and vegetative morphology of this species makes any comparison to other species previously placed in Leandra in the Atlantic Forest very difficult. Moreover, preliminary data placed this species (Michelangeli et al., in prep.) in traditional Miconia s.s.

Even though nowadays this species would be unequivocally placed in Miconia s.1., following its modern circumscription, we have opted to present here the description of the new species along with a simplified phylogeny based on molecular markers, in order to explain its phylogenetic placement and better understand its unique combination of morphological characters.

57

\section{Materials \& Methods}

59 Taxonomy. Specimens from the new species and related ones have been studied in loco in and in the herbaria MBML, NY, RB, UPCB. The specimens from VIES have been checked through images available in virtual herbaria (http://reflora.jbrj.gov.br). All morphological analyses were based on herbarium specimens; floral parts were rehydrated from dried specimens.

Phylogeny. Taxon sampling was based on previous phylogenies that sampled the tribe 
67 based on Cogniaux (1891; see also Michelangeli et al., 2004, 2008; Goldenberg et al., 2008;

68 Reginato \& Michelangeli, 2016); i.e., we showed all the names transferred to a single genus,

69 Miconia s.l., as proposed in Michelangeli et al. (2016, 2019). The old names are listed in Table $70 \mathrm{~S} 1$.

71 Sanger based DNA sequences of M. lucenae (voucher Goldenberg 889) were generated

72 for five molecular markers included in those studies. Total genomic DNA was isolated from

73 silica-dried or herbarium material using the DNeasy Plant Mini Kit (Qiagen, Valencia, CA,

74 USA) following the protocol suggested by Alexander \& al. (2007). The molecular data set

75 included three plastid spacers ( $a t p F-a t p H, p s b K$ - $p s b I$ and $\operatorname{trnS}$-trnG), and two nuclear ribosomal

76 loci (the internal and external transcribed spacers nrITS and nrETS). The amplification protocols

77 and primers used are described in Reginato \& Michelangeli (2016). Cycle sequencing was

78 performed with the same forward and reverse primers used for amplification at the high-

79 throughput sequencing service at the University of Washington (USA). Contigs were assembled

80 with Sequencher 4.9 (GeneCodes Corp., Ann Arbor, MI, USA). An additional plastid gene

$81(n d h F)$ available for most of the sampled taxa was also included in the phylogenetic analysis.

82 Genbank accessions of all taxa analyzed are available in the supplementary Table S1.

83 Sequence alignment was performed with MAFFT v.7 using the strategy G-INS-i (Katoh,

84 2013). DNA substitution models for each of the six makers were selected using jModeltest v.2.1

85 (Darriba et al., 2012), using the 3 model scheme with or without four discrete rate categories

86 approximating a gamma distribution $(+\mathrm{G})$ and including models with equal/unequal base

87 frequencies $(+\mathrm{F})$. The likelihoods were calculated using a Maximum Likelihood optimized base

88 tree with NNI topology search using phyml (Guindon \& Gascuel, 2003) and the models were

89 evaluated using the BIC criterion. Tree inference was performed using a Bayesian framework

90 implemented in the program BEAST v.2.5.0 (Bouckaert et al., 2014). The analysis was

91 performed using the DNA models recovered in the previous step: GTR (atpF-atpH, psbK-psbI);

92 GTR $+\mathrm{G}$ (nrETS, nrITS, trnS-trnG); and HKY+G $(n d h F)$. Tree models were linked across

93 markers, the molecular clock prior was set to the lognormal uncorrelated, and the tree prior was

94 set to the Birth and Death model. Two independent runs of 50 million generations each,

95 sampling every 1,000 generations with a $10 \%$ burn in were performed. Convergence was

96 assessed using Tracer v.1.5 (Rambaut \& Drummond, 2007), and runs had ESS values greater

97 than 200 for all parameters. The stable posterior distributions of the independent runs were 
98 combined using LogCombiner v.2.5.0 and a maximum clade credibility tree summarized with

99 TreeAnnotator v.2.5.0 (Bouckaert et al., 2014).

100 Niche modeling. The potential distribution of $M$. lucenae under current climatic conditions was

101 modeled and evaluated in Maxent 3.4.0 (Phillips \& Dudik, 2008) using the R package dismo

102 (Hijmans et al., 2017). The climatic model was based on its known localities and the 19 climatic 103 variables from the WorldClim data set v.2 with 30" spatial resolution (Fick \& Hijmans, 2017).

104 The area under the curve (AUC) of the receiver operating characteristic (ROC) was used as 105 evaluation criterion, and all parameters were left as the default.

106 Conservation status. Our assessments were based on range size (criterion B), according to the 107 guidelines of the IUCN (IUCN 2012; IUCN Standards and Petitions Subcommittee 2017). Area 108 of Occupancy (AOO) and Extent of Occurrence (EOO) where calculated using the GeoCat tool 109 (Bachman et al. 2011) using the same localities used for Niche modeling.

110 SEM. Seeds and leaves for the SEM images were obtained from herbarium specimens and 111 manually cleaned. The structures were mounted on aluminum stubs, coated with gold-palladium 112 for 2 min in a Hummer 6.2 (Aratech LTD), and examined using a JEOL - JSM 5410LV SEM, 113 with the software JEOL ORION 5410, version 1.72.01 (1999-2004).

114 The electronic version of this article in Portable Document Format (PDF) will represent a 115 published work according to the International Code of Nomenclature for algae, fungi, and plants 116 (ICN), and hence the new names contained in the electronic version are effectively published 117 under that Code from the electronic edition alone. In addition, new names contained in this work 118 which have been issued with identifiers by IPNI will eventually be made available to the Global 119 Names Index. The IPNI LSIDs can be resolved and the associated information viewed through 120 any standard web browser by appending the LSID contained in this publication to the prefix 121 "http://ipni.org/". The online version of this work is archived and available from the following 122 digital repositories: PeerJ, PubMed Central, and CLOCKSS.

\section{Results}

126 Phylogenetic relationships. Miconia lucenae was recovered nested in an early divergent

127 subclade of a clade containing Miconia IV and Miconia V (sensu Goldenberg et al. 2008), all of 128 them sister to the Clidemia/Leandra clade (Fig. 1). Miconia lucenae is resolved in a clade with 
129 M. michelangeliana R.Goldenb. \& L.Kollmann and M. paradoxa (Mart. ex DC.) Triana, called

130 "Paradoxa clade" from now on. Among the other two species in Paradoxa clade, M. lucenae

131 seems closer to M. paradoxa (Fig. 1), which was then chosen as the species to be compared in

132 the formal taxonomic diagnosis.

133

134

Taxonomy

135

136

Miconia lucenae R.Goldenb. \& Michelang., spec. nov.

137 (Figs. 2, 3, 4)

138 Type: Brazil, Espírito Santo: Santa Teresa, Nova Lombardia, Terreno do Furlani, 1947’59’S, 139 40³2'13”'W. 900 m. 7 Feb 2011 (fl, fr), R. Goldenberg. Michelangeli, M.K. Caddah, M.

140 Reginato \& L. Kollmann 1525 (holotype: UPCB -71800; isotypes: MBML, NY- 02104713 ,

141 02104708, RB - 014190053).

142 Diagnosis: Miconia lucenae differs from Miconia paradoxa in terete young branches (vs.

143 strongly decussate-flattened in M. paradoxa), ciliate inner portion of the sepals (vs. eciliate), and 144 lanceolate petals (vs. obovate).

145 Description: Shrubs 0.5-1.5 m tall. All vegetative parts (including both surfaces of the leaf 146 blades), inflorescences and hypanthia very sparsely and caducously covered with (1) stellate 147 trichomes $0.1-0.3 \mathrm{~mm}$ diam, and (2) minute sessile glands, ca. $50 \mu \mathrm{m}$ long. Young stems terete, 148 slightly swollen at the nodes, these usually with a faint interpetiolar line, covered with some 149 stellate trichomes when young, then glabrescent. Leaves isophyllous to slightly anisophyllous; 150 petiole $1.5-4.5 \mathrm{~cm}$ long, glabrous, reddish; blade $4.5-12$ x 2.5-6 cm, oval, elliptic, oval151 lanceolate to lanceolate, apex acuminate (seldom acute), base cordate, truncate or obtuse, 152 sometimes strongly oblique, margins undulate or repand, entire, slightly hyaline (seen from 153 below), and eciliate, membranaceous, flat in fresh material but slightly revolute in dried 154 specimens, green in both surfaces (a bit darker on the adaxial surface) in fresh material, 155 markedly discolor in dried specimens, with the adaxial much darker than the abaxial surface; 156 lateral veins strongly to seldom weakly suprabasal (all specimens have leaves with distinct 157 suprabasal nerves, only Goldenberg 1525 has a few leaves with shortly suprabasal nerves), the 158 inner pair up to $7 \mathrm{~mm}$ distant from the base, with 2 pairs or seldom 4 pairs, plus and additional, 159 faint, marginal pair, sometimes not symmetrically paired (in leaves with oblique bases), main, 160 lateral and transversal veins plane/impressed, reticulation barely perceptible on the adaxial 
161 surface, main, lateral and transversal plane or seldom prominent, reticulation plane but perfectly 162 distinct on the abaxial surface. Panicles 3-6.5 x 2.5-4 cm, terminal, erect, with accessory 163 branches, 2-3 pairs of paraclades, glabrous, the axes reddish; bracts 1-1.5 mm long, linear164 subulate, eciliate, caducous; bracteoles $0.8-1.2 \times 0.2-0.3 \mathrm{~mm}$, linear-lanceolate, curved upwards, 165 persistent. Flowers sessile, 4-merous. Hypanthium 1.4-2 x 1.8-2 mm, greenish-white at anthesis, 166 greener in older flowers and young fruits, narrowly campanulate to shortly terete, both surfaces

167 168 169

170

171

172

173

174

175

176

177

178

179

180

181

182

183

184

185

186

187

188

189

190

191

glabrous; torus glabrous. Calyx persistent, the tube $0.1-0.2 \mathrm{~mm}$ long, greenish-white; sepals with the inner, laminar portion 0.4-0.6 mm long, greenish-white, erect, hemi-circular, apex rounded, margins sparsely ciliate (the cilia thick, less than $0.1 \mathrm{~mm}$ long), otherwise glabrous; outer teeth projecting ca. $0.2 \mathrm{~mm}$ above the laminae, light-green, thick-subulate, the apex acute and very shortly mucronulate, glabrous. Petals, 4, 2-2.2 x 0.7-0.8 mm, white, reflexed at anthesis, and apparently erect in old flowers, lanceolate, apex broadly acute to narrowly rounded, margins undulate, glabrous. Stamens isomorphic, erect, arranged in an actinomorphic bundle; filaments 1.3-1.5 mm long, light yellow, glabrous; anthers ca. 1.5-1.7 mm long, light yellow, oblong in ventral view, with the apex slightly archaed backwards, attenuate, with a minute apical to slightly dorsally inclined pore; connective $0.1-0.2 \mathrm{~mm}$ prolonged below the thecae, yellow (brighter than filaments and anthers), unappendaged or with two dorsal-basal, minute, less than $0.1 \mathrm{~mm}$ long, acute teeth. Ovary ca. $3 \times 3 \mathrm{~mm}$, 4-locular, ca. 2/3 inferior, the free portion projecting ca. $1 \mathrm{~mm}$, broadly rounded, glabrous; style $2.2-2.7 \mathrm{~mm}$ long, filiform, slighly curved, glabrous, stigma punctiform. Berries 3-3.5 x 3-3.5 mm, blackish when ripe, topped with the persistent calyx, glabrous. Seeds $1.1-1.4$ x $0.6-0.8 \mathrm{~mm}$, narrowly pyramidate or narrowly oblong, the raphal region narrow and long, (almost $100 \%$ of the total seed length), testa rough, minutely tuberculate.

Distribution and niche modelling. Miconia lucenae has been collected 6 times in 4 different places, all of them in the Municipality of Santa Teresa, state of Espírito Santo (Fig. 5). Only one of the samples has an indication on elevation $(900 \mathrm{~m})$, but all of them seem to be collected in places with similar elevation. All specimens were collected in shaded areas, in rainforest understory.

The climatic-based distribution model of M. lucenae presented a high value of AUC (0.99). Suitable areas were identified throughout the mountains of Santa Teresa region, especially southern to where the species is known to occur. Additional areas with high suitability 
192 includes the "Caparaó" region (414ㄱ'10"W, 20²6'06"W) and the region of the Municipality of

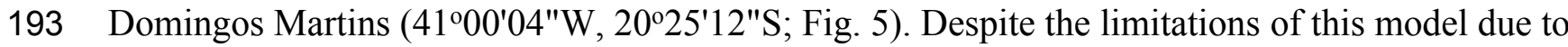
194 the low number of known points for this species, the results can still be informative in the case of 195 collections of this species in new areas.

196 Conservation status. Miconia lucenae has an AOO of $50 \mathrm{~km}^{2}$ and an EOO of $16 \mathrm{~km}^{2}$. Given 197 that the six known collections represent four different sites, but all closely located, and the fact 198 that only one of these is inside a conservation area, we recommend that it is considered as 199 "Endangered" following criteria B1B2abiv (IUCN 2012; IUCN Standards and Petitions 200 Subcommittee 2017).

201 Paratypes. Brazil, Espírito Santo: Santa Teresa, São Lourenço, Country Club, 22 Feb 1999, L. 202 Kollmann, E. Bausen \& W. Pizziolo 1973 (MBML); Santa Teresa, Nova Lombardia, Reserva 203 Biológica, Estrada de Goipaba-Açu, 5 Feb 2002 (fr), L. Kollmann et al. 5484 (MBML, RB, 204 UPCB); Santa Teresa, Nova Lombardia, Reserva Biológica, Estrada para N. Lombardia, 20 Feb 2052002 (fr), L. Kollmann 5594 (MBML, RB, UPCB, VIES); Santa Teresa, Santo Henrique, 22 Jul 2062005 (fr), L. Kollmann \& A.P. Fontana 8160 (MBML, UPCB); Santa Teresa, Nova Lombardia, 207 Terreno do Furlani, 13 Jul 2007 (sterile), R. Goldenberg et al. 889 (MBML, NY, UPCB).

208 Etymology. Miconia lucenae honors Dr. Sérgio Lucena Mendes, a primatologist at the 209 Universidade Federal do Espírito Santo, and more than once director of the Museu de Biologia 210 Mello Leitão / Instituto Nacional da Mata Atlântica, in Santa Teresa. This tribute is deserved by 211 his efforts on biological research, conservation policies in the state of Espírito Santo, and, more 212 importantly, on his belief that the general public, and mostly the "capixabas" (i.e., people and

213 things from Espírito Santo) must understand and value one of the most unknown and

214 undervalued treasures that they have in their own backyards: the wondrously diverse Mata 215 Atlântica.

216

\section{Discussion}

218 Our phylogenetic analysis recovered the same major clades indentified in previous studies 219 (Goldenberg et al., 2008, Michelangeli et al., in prep.). The Paradoxa clade, with Miconia 220 lucenae, M. michelangeliana and M. paradoxa, has not been recognized before. While there is 221 little overall morphological resemblance between $M$. lucenae and the two other species in the 222 Paradoxa clade, all three share glabrous or glabrescent branches and leaves, white petals and 
223 yellow stamens, these with connectives not prolonged below the thecae, which are ventrally 224 unnapendaged, dorsally unnapendagged or have a minute tooth, which are bilobed or not, a 225 glabrous ovary, and fruits with a persistent calyx. Other distinctive characters in the clade are the 226 strongly decussate flattened young branches (in M. michelangeliana and M. paradoxa; lacking in

227 228

229

230

231

232

233

234

235

236

237

238

239

240

241

242

243

244

245

246

247

248

249

250

251

252

253

M. lucenae), and 4-merous flowers with 4-celled gynoecia (in M. lucenae and M. paradoxa; 6merous flowers with 6-celled gynoecia in M. michelangeliana). All three species occur in roughly similar latitudes, two of them endemic to rain forests in Espírito Santo (M. lucenae, M. michelangeliana, the former also in Santa Teresa, to which M. lucenae is endemic), and one endemic to the neighboring state of Minas Gerais, but in "campos rupestres" (i.e., not in rain forests). The differences between the species in Paradoxa clade are summarized in Table 1. In addition to the other members of the Paradoxa clade, Miconia magnipetala (R.Goldenb. \& Camargo) R. Goldenb. (formerly Leandra magnipetala; see Michelangeli et al., 2019) is another species morphologically similar to M. lucenae. Miconia magnipetala, also endemic to forest of Espírito Santo, has not been sampled in our phylogeny, but it shares with M. lucenae 4-merous flowers, persistent sepals in the fruits, each with a distinct internal lamina and an acute external teeth, the broadly lanceolate petals, yellow stamens, and 4-locular ovaries. Despite the unknown phylogenetic position of M. magnipetala, and given some shared morphological traits and geographical distribution, it was also included in Table 1. The inclusion of M. magnipetala in the Paradoxa clade still needs to be tested in a phylogenetic context.

As for its placement in the traditional generic and infra-generic classification in Miconieae (i.e. Cogniaux, 1891), M. lucenae would fit in Leandra sect. Oxymeris (DC.) Cogn., due to the apical inflorescences, lanceolate petals and glabrous vegetative parts. No species in this genus and section has a combination of 4-merous flowers, yellow stamens and 4-celled ovaries. In terms of overall appearance, a species described in Leandra sect. Oxymeris that seems to be morphologically close to M. lucenae is Leandra mourae Cogn. (=Miconia leamourae R.Goldenb.), from montane forests in Rio de Janeiro. This species was chosen by Camargo \& Goldenberg (2011) for the diagnosis of M. magnipetala (see above), but it belongs to the Clidemia/Leandra clade (Reginato \& Michelangeli, 2016). It also has vegetative features similar to M. lucenae, but it has 5-merous, pedicellate flowers with white stamens, longer hypanthia (2.5-3.5. $\mathrm{mm}$ long vs. 1.4-2 $\mathrm{mm}$ in M. lucenae) and external teeth on the sepals (1-2 $\mathrm{mm}$ long vs. ca. $0.2 \mathrm{~mm})$.

Peer] reviewing PDF | (2019:10:42213:2:0:NEW 22 Jan 2020) 
254

255

256

257

258

259

260

261

262

263

264

265

266

267

268

269

270

271

272

273

274

275

276

277

278

279

280

281

282

283

284

\section{Conclusions}

In large and diverse groups such as Miconieae, both morphological and geographical contexts are important to define species. Nevertheless, molecular data may allow to position the species among its relatives. In the case presented here, Miconia lucenae would be placed among species in Leandra s.s. clade due to morphological features and geographic distribution, but the phylogeny places it in a small clade, this apart from the former.

\section{Acknowledgements}

We thank Diana Carneiro for the drawings, and Paulo José Guimarães, Marie Claire VeransoLibalah for their reviews and Mike Thiv for suggestions to previous versions of this manuscript.

\section{References}

Alexander PJ, Rajanikanth G, Bacon CD, Bailey CD. 2007. Recovery plant DNA using a reciprocating saw and silica-based columns. Molecular Ecoloygy Notes. 7: 5-9. DOI: $10.1111 / \mathrm{j} .1471-8286.2006 .01549 . x$

Bachman S, Moat J, Hill AW, de la Torre J, Scott B. 2011. Supporting Red List threat assessments with GeoCAT: geospatial conservation assessment tool. Zookeys 150: 117-126. DOI: 10.3897/zookeys.150.2109

Bouckaert R, Heled J, Kühnert D, Vaughan T, Wu C-H, Xie D, Suchard MA, Rambaut A, Drummond AJ. 2014. BEAST 2: A Software Platform for Bayesian Evolutionary Analysis. PLoS Computational Biology 10 (4), e1003537.

DOI: 10.1371/journal.pcbi.1003537

Camargo EA, Goldenberg R. 2011. Two new species of Leandra from Espírito Santo, Brazil. Brittonia 63: 220-226.

DOI: $10.1007 / \mathrm{s} 12228-010-9154-0$

Cogniaux AC. 1891. Miconieae (Melastomataceae). In: Candolle AP, Candolle C, eds. Monographiae phanerogamarum. Paris: G. Masson, 7: 612-1068.

Darriba D, Taboada GL, Doallo R, Posada D. 2012. jModelTest 2: more models, new heuristics and parallel computing. Nature Methods 9 (8): 772. 
285

286

287

288

289

290

291

292

293

294

295

296

297

298

299

300

301

302

303

304

305

306

307

308

309

310

311

312

313

DOI: $10.1038 /$ nmeth.2109

Fick SE, Hijmans RJ. 2017. WorldClim 2: new 1-km spatial resolution climate surfaces for global land areas. International Journal of Climatology 37 (12): 4302-4315.

$$
\text { DOI: 10.1002/joc.5086 }
$$

Goldenberg R, Penneys D, Almeda F, Judd WS, Michelangeli FA. 2008. Phylogeny of Miconia (Melastomataceae): patterns of stamen diversification in a megadiverse neotropical genus. International Journal of Plant Sciences 169: 963-979.

DOI: $10.1086 / 589697$

Guindon S, Gascuel O. 2003. A simple, fast and accurate method to estimate large phylogenies by maximum-likelihood. Systematic Biology 52: 696-704.

DOI: $10.1080 / 10635150390235520$

IUCN. 2012. IUCN Red List Categories and Criteria: Version 3.1. Second edition. Gland, Cambridge: IUCN

IUCN Standards and Petitions Subcommittee. 2017. Guidelines for using the IUCN Red List Categories and Criteria. Version 13. Available at http://www.iucnredlist.org/documents/RedListGuidelines.pdf (acessed 11 december 2019).

Hijmans RJ, Phillips S, Leathwick J, Elith J. 2017. Dismo: Species Distribution Modeling. R package version 1.1-4 [online]. Available at https://CRAN.R-project.org/package=dismo (accessed 9 August 2019).

Katoh S. 2013. MAFFT multiple sequence alignment software version 7: improvements in performance and usability. Molecular Biology and Evolution 30: 772-780.

DOI: $10.1093 / \mathrm{molbev} / \mathrm{mst} 010$

Kriebel R. 2016. A Monograph of Conostegia (Melastomataceae, Miconieae). PhytoKeys 67: 1326.

DOI: $10.3897 /$ phytokeys.67.6703

Martin CV, Little DP, Goldenberg R, Michelangeli FA. 2008. A phylogenetic evaluation of Leandra (Miconieae, Melastomataceae): a polyphyletic genus where the seeds tell the story, not the petals. Cladistics 24: 315-327.

DOI: 10.1111/j.1096-0031.2007.00185.x 
314 Michelangeli FA, Penneys DS, Giza J, Soltis D, Hils MH, Skean JD. 2004. A preliminary

315

316

317

318

319

320

321

322

323

324

325

326

327

328

329

330

331

332

333

334

335

336

337

338

339

340

341

342

343

344 phylogeny of the tribe Miconieae (Melastomataceae) based on nrITS sequence data and its implications on inflorescence position. Taxon 53: 279-290.

DOI: $10.2307 / 4135608$

Michelangeli FA, Judd WS, Penneys DS, Skean JD, Bécquer-Granados ER, Goldenberg R, Martin CV. 2008. Multiple events of dispersal and radiation of the tribe Miconieae (Melastomataceae) in the Caribbean. Botanical Review 74: 53-77.

Michelangeli FA, Almeda F, Alvear M, Bécquer ER, Burke J, Caddah MK, Goldenberg R, Ionta GM, Judd WS, Majure LC, Meirelles J, Nicolas AN, Ocampo G, Penneys DS, Skean JD, Ulloa-Ulloa C. 2016. Proposal to conserve the name Miconia, nom. cons. against the additional names Maieta and Tococa (Melastomataceae, Miconieae). Taxon 65: 892-893.

DOI: $10.12705 / 673.15$

Michelangeli FA, Goldenberg R, Almeda F, Judd WS, Bécquer ER, Ocampo G, Ionta GM, Skean Jr. JD, Majure LC, Penneys DS. 2019. Nomenclatural novelties in Miconia (Melastomataceae: Miconieae). Brittonia 71: 82-121.

DOI: 10.1007/s12228-018-9546-0 (online first, 2018)

Phillips SJ, Dudík M. 2008. Modeling of species distributions with Maxent: New extensions and a comprehensive evaluation. Ecography 31: 161-175.

DOI: $10.1111 / \mathrm{j} .0906-7590.2008 .5203 . \mathrm{X}$

Rambaut A, Drummond AJ. 2007. Tracer. Available at http://www.beast.bio.ed.ac.uk/Tracer (accessed 28 Sep 2017).

Reginato, M. 2016. Taxonomic revision of Leandra sect. Leandra (Melastomataceae, Miconieae). Phytotaxa 262: 1-97.

DOI: $10.11646 /$ phytotaxa.262.1.1

Reginato M, Michelangeli FA. 2016. Untangling the phylogeny of Leandra s.str.

(Melastomataceae, Miconieae). Molecular Phylogenetics and Evolution 96: 17-32. DOI: 10.1016/j.ympev.2015.11.015. 


\section{Table $\mathbf{1}$ (on next page)}

Comparative features among Miconia lucenae and relatives in clade paradoxa.

Comparative features among Miconia lucenae and relatives in clade paradoxa plus Miconia magnipetala, a species that is morphologically similar, but not sampled in the phylogeny. The table includes the Brazilian state to which they were recorded and vegetation type. The table does not include characters that are shared by all four species, such as the glabrous or glabrescent branches and leaves, white petals and yellow stamens, these with the connectives not prolonged bellow the thecae, glabrous ovary, and the fruits with a persistent calyx. 


\begin{tabular}{|c|c|c|c|c|}
\hline Character/Species & M. lucenae & M. magnipetala & M. michelangeliana & M. paradoxa \\
\hline Young branches, shape & $\begin{array}{l}\text { small shrubs, up to } \\
1.5 \mathrm{~m} \text { tall } \\
\text { terete }\end{array}$ & $\begin{array}{l}\text { small shrubs, up to } 1 \\
\mathrm{~m} \text { tall } \\
\text { terete }\end{array}$ & $\begin{array}{l}\text { trees, } 8-12 \mathrm{~m} \text { tall } \\
\text { strongly flattened- } \\
\text { decussate }\end{array}$ & $\begin{array}{l}\text { small shrubs, up to } 1.5 \\
\mathrm{~m} \text { tall } \\
\text { strongly flattened- } \\
\text { decussate }\end{array}$ \\
\hline $\begin{array}{l}\text { Number of bracetoles per } \\
\text { flower }\end{array}$ & 2 & 4 & 2 & 2 \\
\hline Pedicel & absent & $2-4,5 \mathrm{~mm}$ long & absent & absent \\
\hline $\begin{array}{l}\text { Flower, number of parts } \\
\text { Calyx tube/sepals inner } \\
\text { portion margins }\end{array}$ & $\begin{array}{l}\text { 4-merous } \\
\text { ciliate }\end{array}$ & $\begin{array}{l}\text { 4-merous } \\
\text { glabrous }\end{array}$ & $\begin{array}{l}\text { 6-merous } \\
\text { glabrous }\end{array}$ & $\begin{array}{l}\text { 4-merous } \\
\text { glabrous }\end{array}$ \\
\hline Calyx outer teeth & distinct & distinct & not perceptible & distinct \\
\hline Petals shape/ apex & $\begin{array}{l}\text { lanceolate / broadly } \\
\text { acute to narrowly } \\
\text { rounded }\end{array}$ & $\begin{array}{l}\text { broadly lanceolate / } \\
\text { acute }\end{array}$ & $\begin{array}{l}\text { oblong to } \\
\text { oblanceolate / } \\
\text { rounded }\end{array}$ & $\begin{array}{l}\text { obovate / obtuse to } \\
\text { rounded }\end{array}$ \\
\hline $\begin{array}{l}\text { Stamen connective, } \\
\text { appendages }\end{array}$ & $\begin{array}{l}\text { unnapendaged or } \\
\text { with a small bilobed } \\
\text { dorsal tooth }\end{array}$ & unappendaged & $\begin{array}{l}\text { unappendaged or } \\
\text { with two small dorsal } \\
\text { teeth }\end{array}$ & unappendaged \\
\hline Ovary, number of locules & 4-celled & 4-celled & 6-celled & 4-celled \\
\hline Distribution/vegetation & $\begin{array}{l}\text { Espírito Santo / } \\
\text { rainforest }\end{array}$ & $\begin{array}{l}\text { Espírito Santo / } \\
\text { rainforest }\end{array}$ & $\begin{array}{l}\text { Espírito Santo / } \\
\text { rainforest }\end{array}$ & $\begin{array}{l}\text { Minas Gerais / } \\
\text { "campo rupestre" }\end{array}$ \\
\hline
\end{tabular}




\section{Figure 1}

Maximum clade credibility tree from the stable posterior distribution (BEAST), including the newly described $M$. lucenae and representatives of major clades in tribe Miconieae

Maximum clade credibility tree from the stable posterior distribution (BEAST), including the newly described M. lucenae and representatives of major clades in tribe Miconieae (Goldenberg et al., 2008). Posterior probabilities values for nodes follow the legend. 


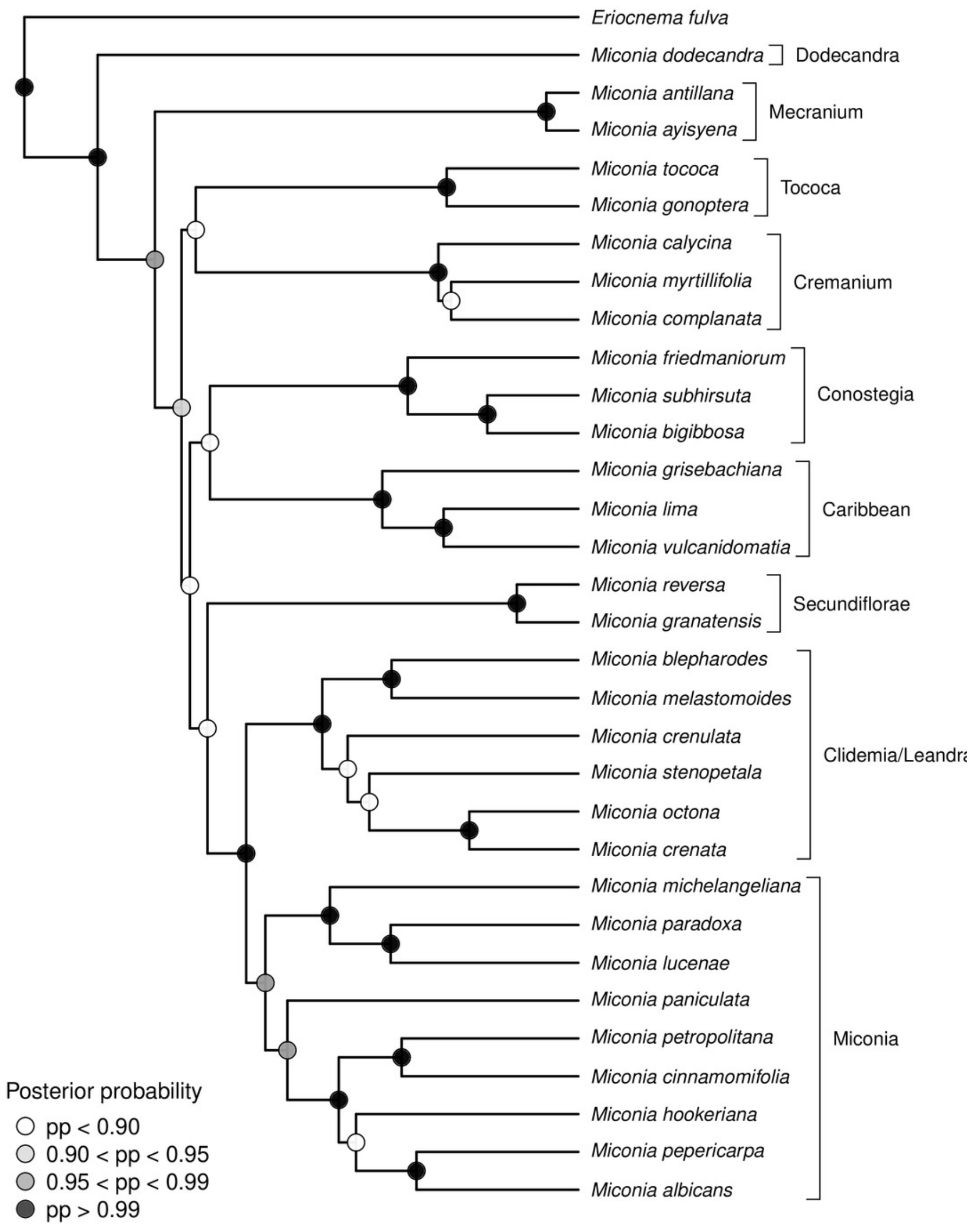


Figure 2

Illustration of Miconia lucenae

Miconia lucenae. A. Fertile branch. B. Leaf base, abaxial view. C. Petal, adaxial view. D.

Stamens, lateral (left) and dorsal (right) views. E. Old flower (petals and stamens removed) with bracteoles, and detail of the sepal, abaxial view. F. Old flower (petals and stamens removed), longitudinal section. G. Fruit. H. Seeds. A-H from Goldenberg 1525 (UPCB). Illustration by Diana Carneiro. 


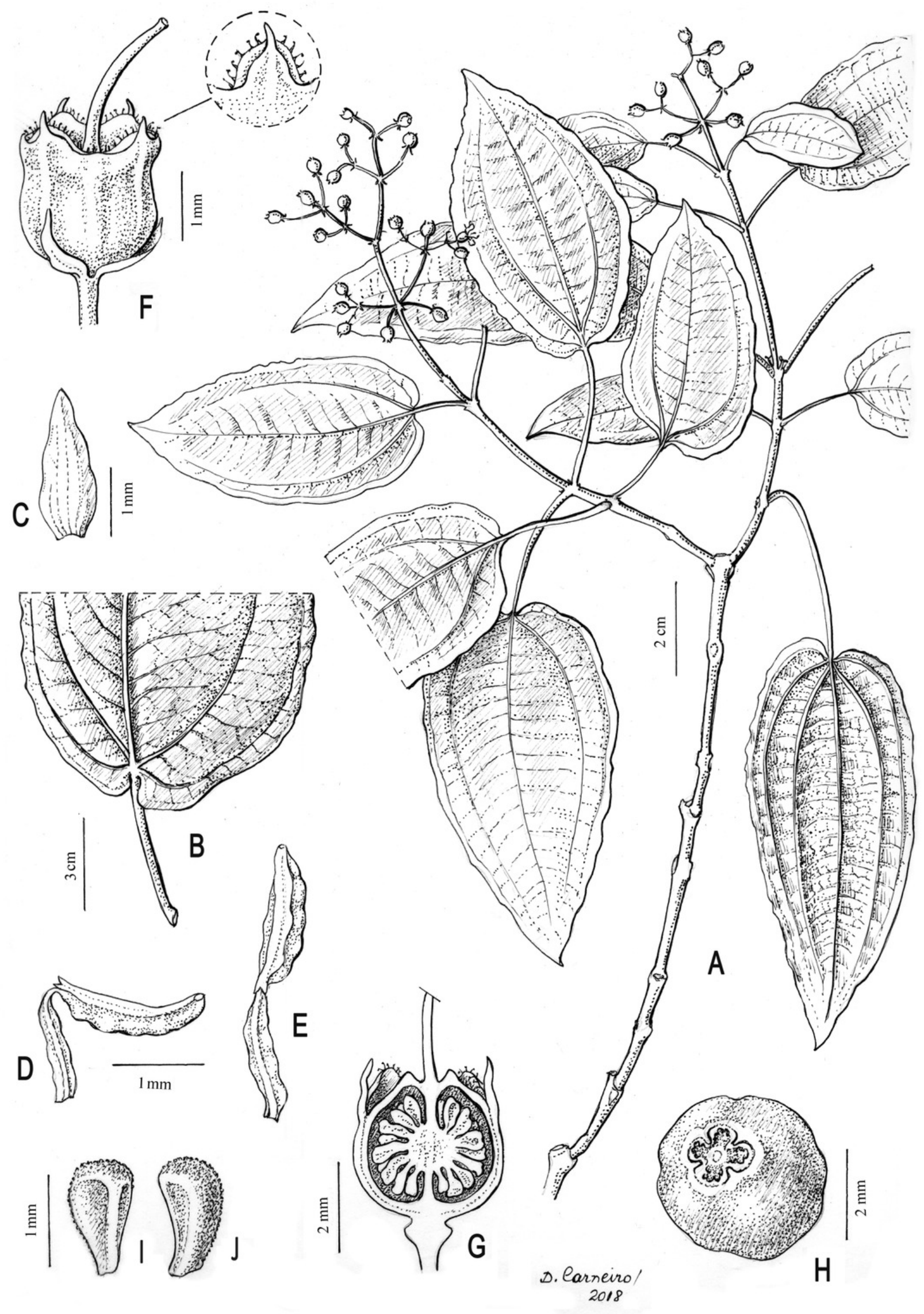




\section{Figure 3}

Photos of living plants of Miconia lucenae

Miconia lucenae, living plants. A. Leaf, abaxial view. B. Inflorescence. C. Flower, lateral view, and young fruit, top view. D. Old flower (with persistent petals and stamens), lateral view. E. Inflorescence branch with flowers and young fruits. F. Leaf, abaxial view. A-F from Goldenberg 1525 (UPCB). Photos by F. Michelangeli. 

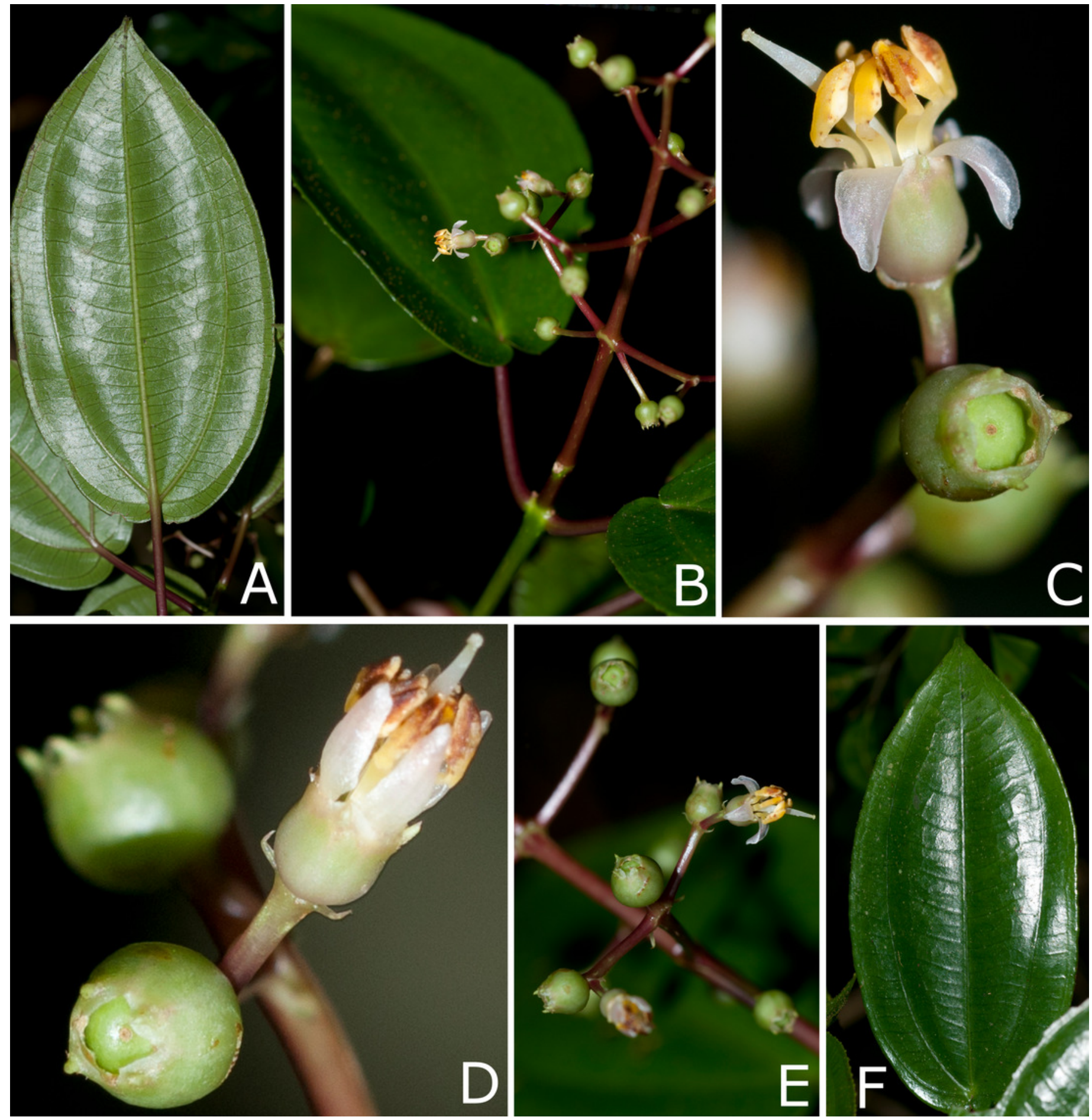


\section{Figure 4}

SEM images of trichomes and seeds of Miconia lucenae

SEM of the leaf surface and seeds of Miconia lucenae. A. Leaf, adaxial surface, with trichomes and sessile glands. B. Sessile gland. C-D. Stellate trichomes. E Seed, lateral view. F. Seed, testa surface. All from L. Kollmann 5594 (NY).
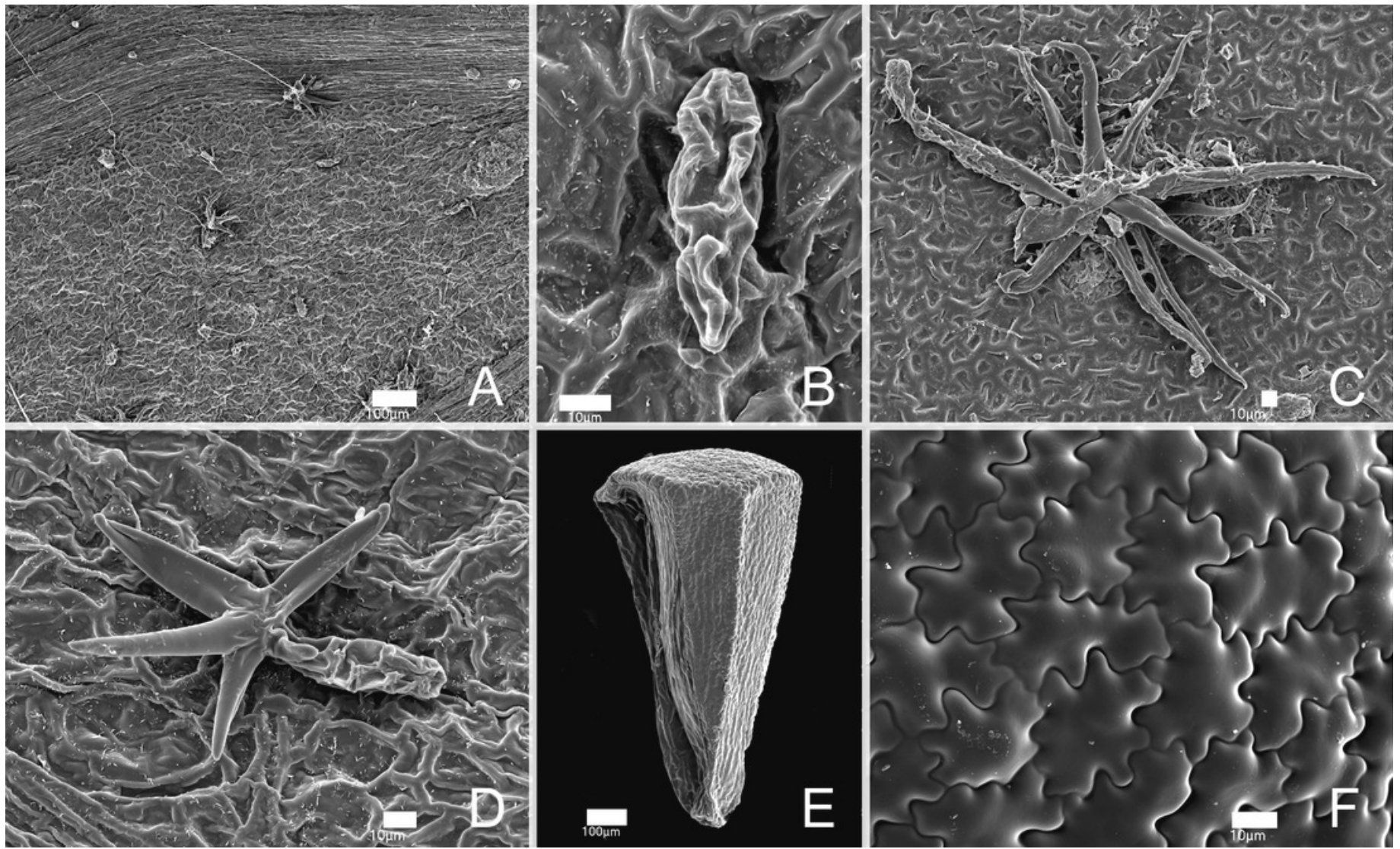


\section{Figure 5}

Geographic distribution and predicted suitable areas under current climatic conditions of Miconia lucenae.

Geographic distribution of Miconia lucenae. Known distribution is indicated by the point localities and predicted suitable areas under current climatic conditions are in red tones following the legend.

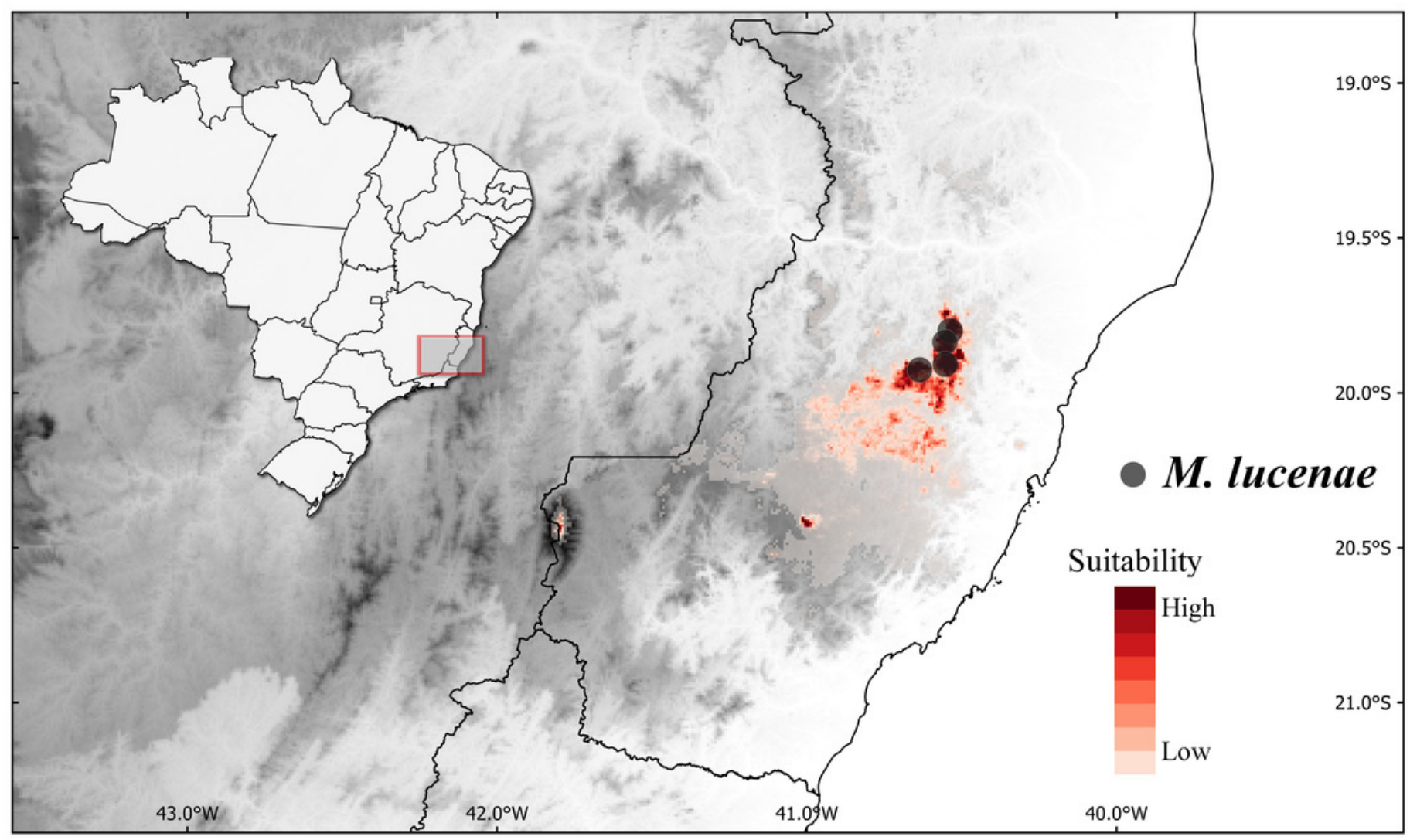

